\title{
Histopathological Characterization of the Skeletal Myopathy in rasH2 Mice Carrying Human Prototype c-Ha-ras Gene
}

\author{
Takayuki TSUCHIYA ${ }^{1) *}$, Miyoko OKADA ${ }^{1)}$, Tetsuya SAKAIRI ${ }^{1}$, Fumiko SANO $^{1)}$, Jiro SUGIMOTO ${ }^{1)}$ and \\ Shirou TAKAGI ${ }^{1)}$ \\ ${ }^{1)}$ Toxicology Laboratory, Pharmaceuticals Research Center, Mitsubishi Pharma Corporation, 1-1-1 Kazusakamatari, Kisarazu, Chiba \\ 292-0818, Japan
}

(Received 8 October 2004/Accepted 5 January 2005)

ABSTRACT. A skeletal myopathy is found in approximately $100 \%$ of rasH2 mice. To confirm detailed features of the rasH2 skeletal myopathy, the biceps femoris, diaphragm, triceps brachii, gastrocnemial (types I and II fiber-mixed muscles) and soleus muscle (type I fiberdominant muscle) obtained from male rasH2 and non-transgenic littermates aged 10-13 and 34 weeks were examined. Variations in the muscle fiber size, early-scattered degeneration/necrosis and regeneration of muscle fibers were detected in 10-13-week-old rasH2 mice. The severity of the above muscular lesions was more prominent in older rasH2 mice. These lesions were noted in the type II myofiber dominant muscles (biceps femoris, triceps brachii and gastrocnemial). NADH-TR stain clearly demonstrated a disorganized intermyofibrillar network and necrotic change in muscle fibers. No specific morphological changes, like rod structure or tubular aggregation seen in some types of myopathy, were noted in Gomori trichrome and NADH-TR stains in the rasH2 mouse like in many types of muscular dystrophy. Electronmicroscopically, occasional muscle fiber degeneration/regeneration, invaded phagocytic cells, indistinct Z-band suggesting excessive contraction and dilatation of the sarcoplasmic reticulum were observed. In summary, the skeletal myopathy occurring in rasH2 mice is consistent with muscular dystrophy characterized morphologically by progressive degeneration and regeneration of myofibers. The myopathy is confined to the type II myofiber predominant muscles and is not associated with any pathognomonic lesions. These characteristics will provide us with a useful model for research in muscular dystrophy of diverse myofibers. KEY WORDS: histopathology, rasH2 mouse, skeletal myopathy.

Various types of neuromuscular diseases are known in both human and animal. There are some different classifications based on the pathogenesis of the diseases in human, however, they can be briefly categorized into congenital myopathies, muscular dystrophies, inflammatory myopathies, metabolic myopathies, denervating disease and other miscellaneous diseases [14]. The categorization of neuromuscular disease in laboratory animal is similar to that of human [20]; nutritional diseases and infectious myositis are considered to have much more significance compare to that in human.

Neuromuscular diseases vary in their histopathologic characteristics. On the diagnosis of neuromuscular disease, it is important to identify whether the disease is neurogenic disorders, which have their primary abnormality in the motor neuron, or myopathic disorders, in which the primary defect is in the muscle fibers [30]; that can be discernable by identifying histologic features of the diseases. In metabolic myopathies, an accumulation of glycogen or lipid in myofibers is a fundamental characteristic of the diseases. To proof accumulation of these substances in myofibers by using histochemical techniques is pivotal for the diagnosis of the metabolic myopathy. Besides, some diseases show non-specific myofiber degeneration $[5,14,16]$, the others show specific pathognomonic lesions like in some congenital myopathies in human $[12,25]$. Therefore, to identify his-

\footnotetext{
* Correspondence to: Tsuchiya, T., Tsukuba Safety Assessment Laboratories, Banyu Pharmaceutical Co., Ltd., 3 Okubo, Tsukuba, Ibaraki 300-2611, Japan.
}

topathologic features of the neuromuscular diseases significantly contributes to its diagnosis.

The muscular disease group based on gene abnormalities that characterized by progressive muscle wasting and weakness is muscular dystrophy, and is recognized in humans and animals. The one unifying feature of dystrophy is the muscle histological findings, with variations in fiber size, fiber necrosis, invasion by macrophages, and ultimately, replacement by fat and connective tissue [11]. According to the genetic basis, human muscular dystrophy has now been reclassified and close to 30 genes have been implicated as the cause of muscular dystrophy [5]. Mutations in several individual genes are now known to underlie the pathogenesis of different types of muscular dystrophy [13, 15, 40]. Duchenne muscular dystrophy is the most common form of $\mathrm{X}$-linked recessive muscular dystrophy, and is characterized by the absence of the protein, dystrophin, in skeletal muscles [16].

Inherited muscular dystrophy has also been identified in animals [2-4, 6, 19, 43]. X chromosome-linked muscular dystrophy $(m d x)$ was identified in the C57BL/10ScSn colony [3]. Dystrophin has not been identified in the $m d x$ mouse [16]. The $m d x$ mouse has been the focus in the past two decades because of its genetic similarity to Duchenne muscular dystrophy (DMD) in humans. These mouse models have significantly contributed to the elucidation of the pathogenesis of muscular dystrophy.

We have previously reported that approximately $100 \%$ of transgenic mice carrying the human prototype c-Ha-ras 
gene, $\mathrm{CB} 6 \mathrm{~F} 1-\mathrm{Tg}$ rasH2 mice (rasH2 mice) have naturally occurring skeletal myopathy in both males and females [37]. Three copies of the transgene were integrated into the genome of this mouse, and were located on chromosome $15 \mathrm{E} 3$ [35] and the structure of the integrated transgene in rasH2 mice was described in detail by Saitoh et al. [31]. These mice are intended as an alternative model for 2-year carcinogenicity studies $[29,35,43]$.

Although the transgene of rasH2 mice is unequivocally involved in myopathy in this animal model, the underlying mechanism of action is not yet elucidated. Nor were there any histopathological characterization in detail for the myopathy. This communication describes morphological features with a particular attention being placed on the classification of the myofiber type affected in rasH2 mice.

\section{MATERIALS AND METHODS}

Nine male rasH2 mice and 9 male non-transgenic littermates (non-Tg mice) (Central Institute of Experimental Animals, Kawasaki, Japan) were housed in a polycarbonate cage with hard wood chips and maintained in an environment-controlled animal room with a 12/12-hr light/dark cycle until aged 10-13 weeks or 34 weeks old. Food (CRF1, Oriental Yeast Co., Tokyo, Japan) and tap water were provided ad libitum. Animals were sacrificed under diethylether anesthesia. All mice used in this study were treated according to the rules described in the Standards Relating to the Care and Management of Experiment Animals (1980, Prime Minister's Office, Japan).

Necropsy and histopathology: Sampling details are summarized in Table 1. At necropsy, the diaphragm, biceps femoris, triceps brachii and gastrocnemial (with soleus) muscle from three rasH2 and Non-TG mice aged 10 weeks and 34 weeks were isolated, fixed in $10 \%$ neutral buffered formalin. These muscles were embedded in paraffin, sectioned and stained with hematoxylin and eosin (HE) stain. The biceps femoris muscles from three each of rasH2 and Non-TG mice aged 10 to 13 weeks were isolated and quickly frozen in liquid nitrogen. Cryosections $(10 \mu \mathrm{m})$ of the biceps femoris muscles were stained with HE stain, modified Gomori trichrome and NADH-TR stain, and were examined microscopically. Small pieces of the biceps femoris muscle from rasH2 and Non-TG mice aged 10 to 13 weeks were fixed in $2.5 \%$ glutaraldehyde in $0.2 \mathrm{M}$ phosphate buffer ( $\mathrm{pH} 7.4$ ), and were post-fixed in $1 \%$ osmium tetroxide and embedded in epoxy resin blocks. Ultra-thin sections were stained with uranyl acetate and lead citrate. Samples were subjected to electron microscopic examination using a Hitachi H-7500 electron microscope (Hitachi High-Technologies Corporation).

\section{RESULTS}

Light microscopy: The incidences of myopathic lesions are summarized in Table 2. In rasH2 mice aged 10 to 13 weeks, myopathic changes were seen in the biceps femoris, gastrocnemial and triceps brachii muscles. The biceps femoris muscle was more susceptible than other muscles. Variations in muscle fiber size, scattered degeneration/necrosis of muscle fibers, and centrally nucleated fibers, suggesting the regeneration of muscle fibers, were observed in the transverse section of the biceps femoris (Fig. 1). Muscular degeneration/necrosis was occasionally accompanied by increased cell density, representing most likely the satellite cell proliferation (Figs. 2d and e). There was no inflammatory lymphocytic infiltration around the intact muscle and perivascular area. In gastrocnemial and triceps brachii muscles, variations in muscle fiber size were noted (Table 2). No abnormality was seen in the diaphragm and soleus muscle. The reaction of endomysial connective tissue was limited. In NADH-TR stain, neither myopathic grouping of regenerating muscle fibers, apparent abnormality in the muscle fiber type differentiation, nor fiber-type grouping suggesting denervation of the muscle fiber were observed in affected muscles (Figs. 1c and d). The disorganization or collapse of the internal architecture of muscle fibers was clearly demonstrated (Figs. $2 \mathrm{f}$ and i). In rasH2 mice aged 34 weeks, myopathic changes were more prominent and widespread than in those aged 10 to 13 weeks old, and confirmed in all of rasH2 mice examined. Necrotic or degenerative muscle fibers were more evident in rasH2 mice of this age (Fig. 3), and no myopathic changes were observed in the soleus muscle and diaphragm.

Table 1. Sampling of muscles from rasH2 and non-TG mice

\begin{tabular}{lcccccccc}
\hline & Age of animals & \multicolumn{3}{c}{$10-13$} & week & \multicolumn{2}{c}{34 week } \\
\hline \multicolumn{1}{c}{ Genotype } & Non-TG & rasH2 & Non-TG & rasH2 \\
\hline Muscles & Number of animals & 3 & 3 & 3 & 3 & 3 & 3 \\
\hline Biceps femoris & $\mathrm{F}$ & $\mathrm{P}$ & $\mathrm{F}$ & $\mathrm{P}$ & $\mathrm{P}$ & $\mathrm{P}$ \\
\hline Gastrocnemial muscle & - & $\mathrm{P}$ & - & $\mathrm{P}$ & $\mathrm{P}$ & $\mathrm{P}$ \\
\hline Soleus muscle & - & $\mathrm{P}$ & - & $\mathrm{P}$ & $\mathrm{P}$ & $\mathrm{P}$ \\
\hline Diaphragm & - & $\mathrm{P}$ & - & $\mathrm{P}$ & $\mathrm{P}$ & $\mathrm{P}$ \\
\hline Triceps brachii muscle & - & $\mathrm{P}$ & - & $\mathrm{P}$ & $\mathrm{P}$ & $\mathrm{P}$ \\
\hline
\end{tabular}

F, Frozen for cryosections, P, Fixed in Formalin for paraffin sections, -, Not performed. 


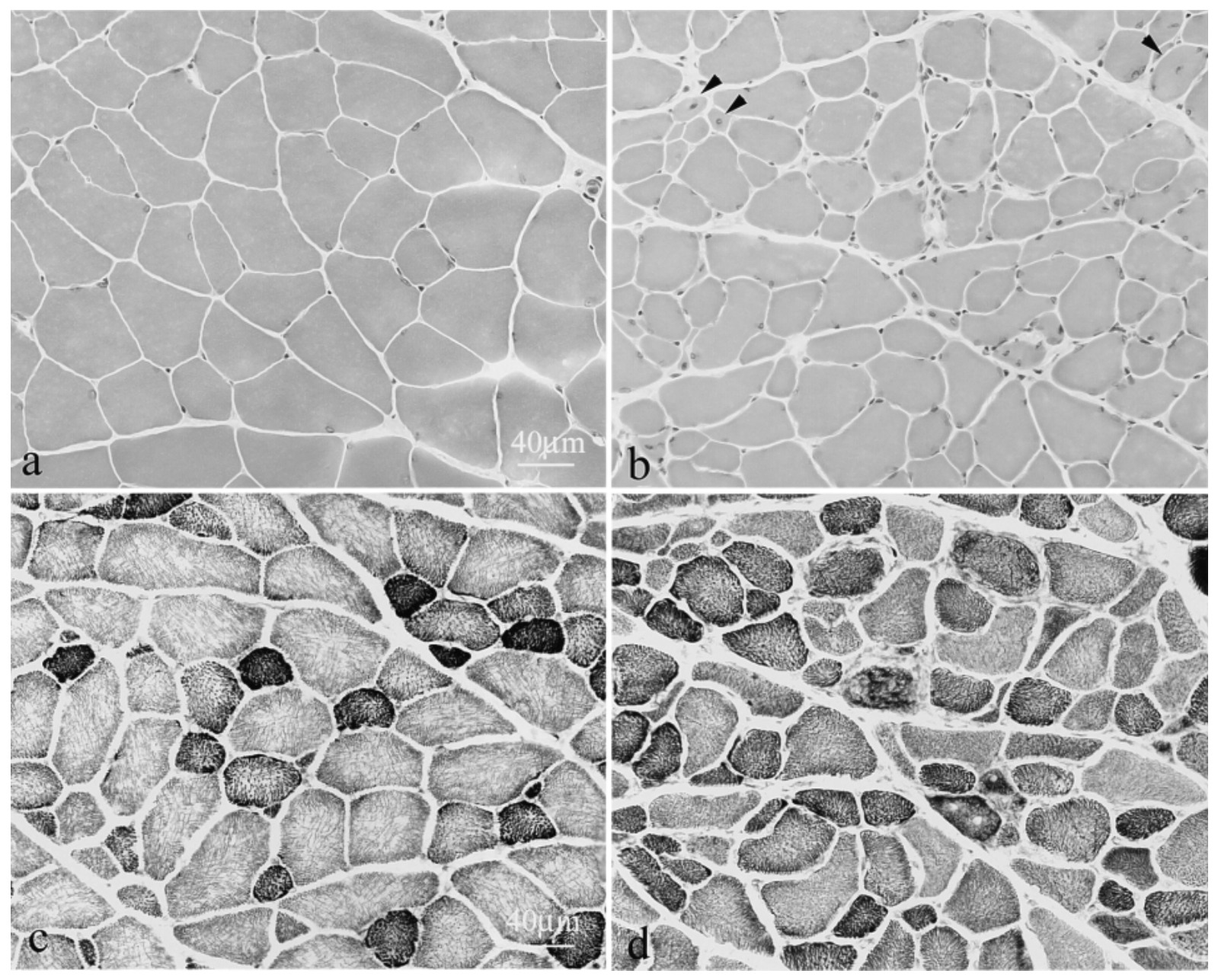

Fig. 1. Histochemical analysis of cryosections of skeletal muscles of 10-week-old Non-Tg mice (a and c) and 13-week-old rasH2 mice (b and d). HE ( $a$ and $b$ ) and NADH-TR (c and d) staining of the biceps femoris muscle. No abnormality in the biceps femoris muscle of 10-week-old Non Tg-mice (a and c). Biceps femoris muscle of 13-week-old rasH2 mice. Variation of muscle fiber size was evident in the transverse section of the muscle fibers and the centrally placed nuclei (arrow heads) were noted (b). In NADH-TR stain, no fiber type grouping was noted in rasH2 mice (d).

Electron microscopy: In 10-13-week-old rasH2 mice, dilatation of the sarcoplasmic reticulum, which was not accompanied with morphological abnormality in any other organelle, was observed as an early change (Fig. 4b). Invaded phagocytic cells were seen at the periphery of degenerative/regenerative muscle fibers (Fig. 4d), and an indistinct Z-band suggesting excessive contraction was observed (Fig. 4f). There was no abnormality in Non-Tg mice.

\section{DISCUSSION}

This is the first report of the detailed histopathological characterization of skeletal myopathy in rasH2 mice using histochemical and electronmicroscopical analysis. We have previously reported that skeletal myopathy was seen in approximately $100 \%$ of 34 -week-old rasH2 mice with no gender difference. In this study, we examined both young (10-13-weeks-old) and relatively old (34-week-old) male rasH2 mice. The observation of young animals may clarify the early change in rasH2 skeletal myopathy. In 10 or 13week-old rasH2 mice, myopathic changes were relatively mild; degenerative/necrotic muscle fibers were noted only in the biceps femoris muscle. In other muscles, only variations in muscle fibers were recognized. Therefore, 10 to 13 weeks of age was considered the onset of muscular degeneration in rasH2 mice. Microscopically, muscular lesions in the biceps femoris consisted of muscle fiber degeneration/ necrosis, a phagocytic reaction to affected fibers and regeneration that was essentially similar to the features of muscular dystrophy. No inflammatory cell infiltration was confirmed around the intact muscle fibers or vessels unlike in polymyositis and dermatomyositis. Therefore, rasH2 skeletal myopathy should be differentiated from inflamma- 

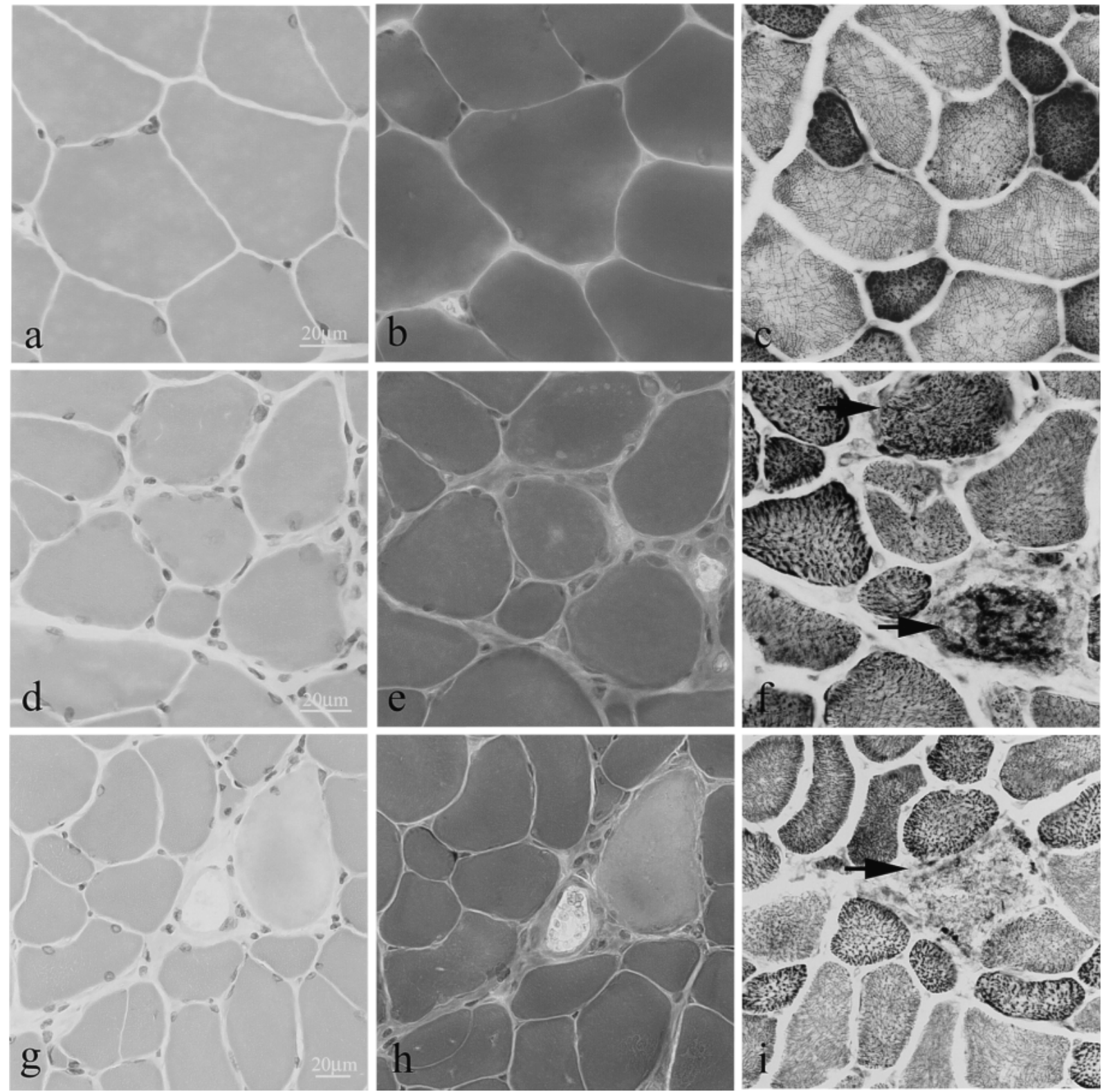

Fig. 2. Histochemical analysis of cryosections of skeletal muscles of 10-week-old Non-Tg mice (a-c) and 13-week-old rasH2 mice (d-i). HE (a, d and g), Gomor trichrome ( $b$, e and h) and NADH-TR (c, f and i) staining of the biceps femoris muscle. No abnormality in the biceps femoris muscle of 10-week-old Non Tg-mice (a-c). Biceps femoris muscle of 13-week-old rasH2 mice. Muscular degeneration/ necrosis was occasionally accompanied by increased cell density, representing most likely the satellite cell proliferation (d and e). Pale, necrotic muscle fibers were sometimes seen ( $\mathrm{g}$ and $\mathrm{h}$ ). In NADH-TR stain, muscle fibers with disorganization or collapse (arrows) of intermyofibrillar network were seen (f and i). Specific morphological changes, such as rod structure or tubular aggregation suggesting a specific type of myopathy, were not observed in rasH2 mice (e, f, h and i).

Fig. 3. Gastrocnemial muscle (G; type I and II fiber mixed muscles) and soleus muscle (S; type I fiber dominant muscle) from a 34-weekold male Non-Tg mouse (a-c) and rasH2 mouse (d-f). HE staining (paraffin sections). Myopathic lesions, such as variations of muscle fiber size, central placed nuclei, degeneration of muscle fibers, and infiltration of granulocytes and macrophages, were seen in gastrocnemial muscles, but not in the soleus muscle (e). 

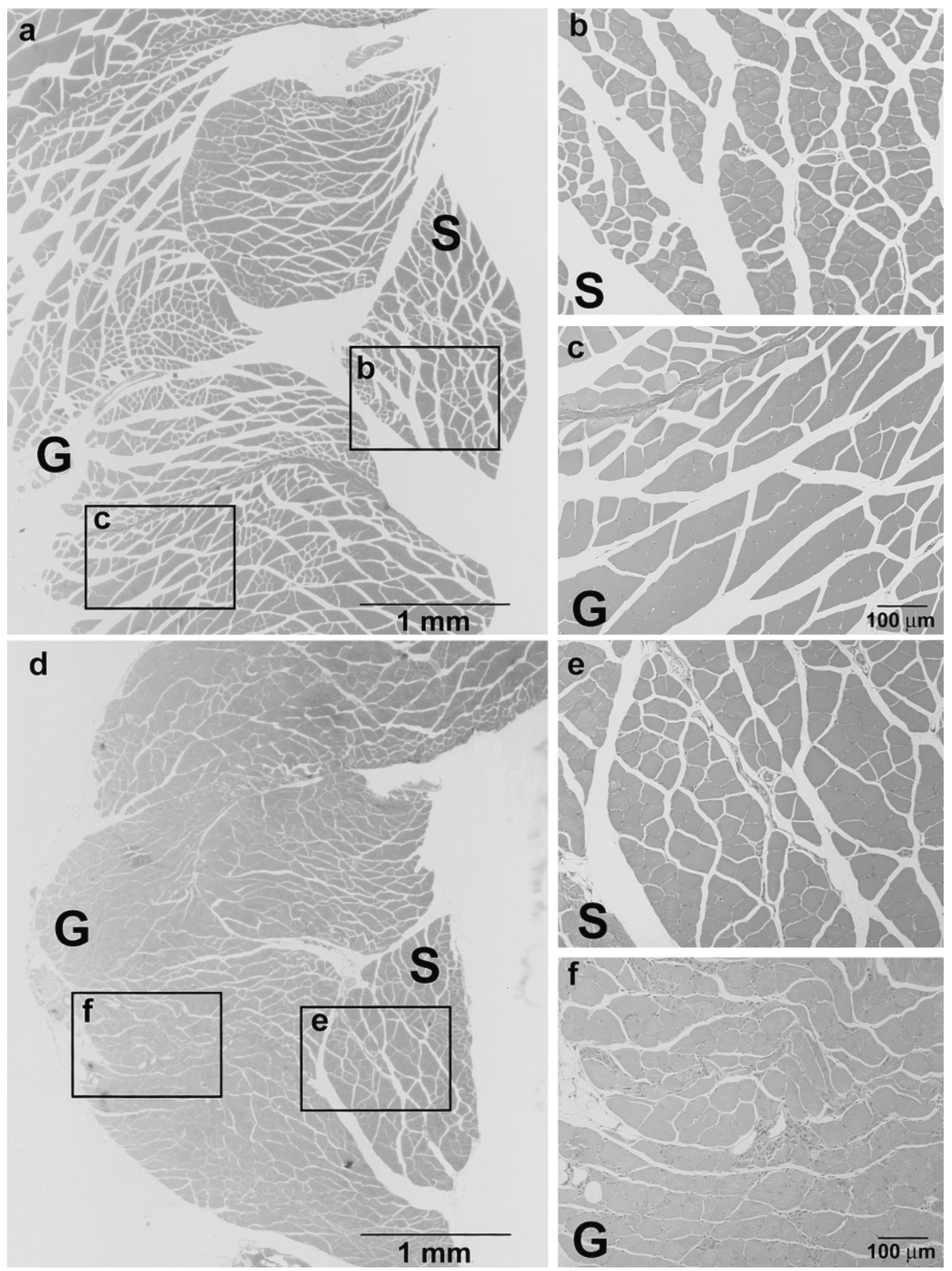

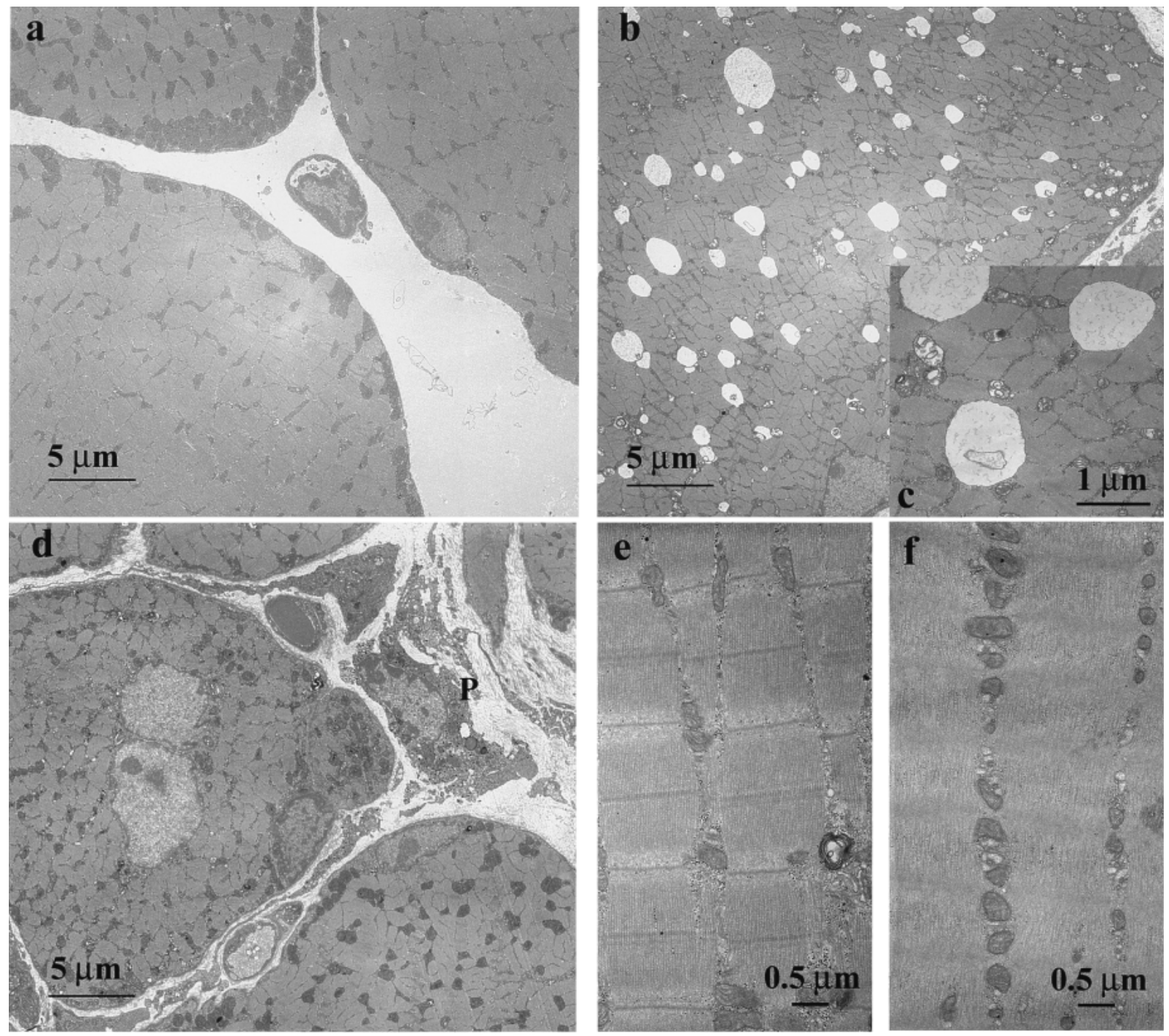

Fig. 4. No abnormality in Non-Tg (a and e). A muscle fiber with dilatation of the sarcoplasmic reticulum was seen (b and c). Other organelles and cytoplasmic structure were preserved normally in muscle fibers (b and c). Invaded phagocytic cell was seen at the periphery of degenerative/regenerative muscle fibers (d). Indistinct Z-bands suggesting excessive contraction were seen (f).

tory myopathy.

In some types of human skeletal myopathy, the typical morphological architecture in skeletal muscles is known to be an important feature in the diagnosis of myopathy. For example, rod structures in Nemaline myopathy, and core structures in central core disease, are specific changes in each type of skeletal myopathy. These morphological changes are clearly demonstrated by Gomori trichrome or NADH-TR stains. On the other hand, it is known that many types of muscular dystrophies including DMD, and animal muscular dystrophies show non-specific muscle fiber degeneration/necrosis without any specific morphological changes $[5,14,16]$. In our observations, using these special stains, no typical structures were noted in the rasH2 mouse like in the major type of muscular dystrophies such as
DMD.

Skeletal muscles exhibit a heterogeneous response to muscular degeneration in rasH2 mice. Muscular lesions were observed in the biceps femoris, gastrocnemial muscle and triceps brachii muscle, but not in the soleus muscle and diaphragm. We have confirmed myopathic change in the muscles from abdominal wall (unpublished data) and pectoral muscle [37]. The striated muscle in the esophagus, tongue and heart were not affected [37]. The $m d x$ mouse is also known to exhibit a heterogeneous response to muscular dystrophy. It is the most widely used animal model of DMD, and dystrophin deficiency was subsequently identified [3]. In $m d x$ mice, extra ocular muscles are completely spared, hind limb muscles undergo a progressive dystrophic process throughout their lifespan, and the diaphragm shows 
Table 2. Incidence of myopathic lesions in light microscopic observations

\begin{tabular}{|c|c|c|c|c|c|}
\hline \multirow[b]{3}{*}{ Muscles } & \multirow{2}{*}{$\begin{array}{c}\text { Age of animals } \\
\text { Genotype }\end{array}$} & \multicolumn{2}{|c|}{$10-13$ week } & \multicolumn{2}{|c|}{34 week } \\
\hline & & Non-TG & rasH2 & Non-TG & $\mathrm{rasH} 2$ \\
\hline & Number of animals & 6 & 6 & 3 & 3 \\
\hline Biceps femoris & Number examined & $<6>$ & $<6>$ & $<3>$ & $<3>$ \\
\hline \multicolumn{2}{|c|}{ Variation of muscle fiber size } & 0 & 5 & 0 & 3 \\
\hline \multicolumn{2}{|c|}{ Degeneration/necrosis of muscle fibers } & 0 & $1^{*}$ & 0 & 3 \\
\hline \multicolumn{2}{|c|}{ Centrally nucleated fibers } & 0 & 5 & 0 & 3 \\
\hline \multicolumn{2}{|c|}{ Mononuclear cell infiltration } & 0 & 0 & 0 & 3 \\
\hline Gastrocnemial muscle & Number examined & $<3>$ & $<3>$ & $<3>$ & $<3>$ \\
\hline \multicolumn{2}{|c|}{ Variation of muscle fiber size } & 0 & 3 & 0 & 3 \\
\hline \multicolumn{2}{|c|}{ Degeneration/necrosis of muscle fibers } & 0 & 0 & 0 & 3 \\
\hline \multicolumn{2}{|c|}{ Centrally nucleated fibers } & 0 & 0 & 0 & 3 \\
\hline \multicolumn{2}{|c|}{ Mononuclear cell infiltration } & 0 & 0 & 0 & 3 \\
\hline Triceps brachii muscle & Number examined & $<3>$ & $<3>$ & $<3>$ & $<3>$ \\
\hline \multicolumn{2}{|c|}{ Variation of muscle fiber size } & 0 & 3 & 0 & 3 \\
\hline \multicolumn{2}{|c|}{ Degeneration/necrosis of muscle fibers } & 0 & 0 & 0 & 3 \\
\hline \multicolumn{2}{|c|}{ Centrally nucleated fibers } & 0 & 0 & 0 & 3 \\
\hline \multicolumn{2}{|c|}{ Mononuclear cell infiltration } & 0 & 0 & 0 & 3 \\
\hline \multirow[t]{2}{*}{ Soleus muscle } & Number examined & $<3>$ & $<3>$ & $<3>$ & $<3>$ \\
\hline & & - & - & - & - \\
\hline \multirow[t]{2}{*}{ Diaphragm } & Number examined & $<3>$ & $<3>$ & $<3>$ & $<3>$ \\
\hline & & - & - & - & - \\
\hline
\end{tabular}

more severe pathology at all life stages [9, 10, 24, 26, 27]. The inbred Bio 14.6 hamster is a recessively inherited dystrophic myopathy model where both cardiac and skeletal muscles are affected [17]. The genetic cause for dystrophic disease in the Bio 14.6 hamster was identified as a loss-offunction mutation of the $\delta$-SG gene $[21,32]$.

In humans, different muscle groups do not respond in the same ways to muscular disease. Examples of restricted disease patterns are found among the limb girdle muscular dystrophy and metabolic myopathy [11]. Thus differential targeting in muscular dystrophy is well documented in animals and humans, however, the mechanisms responsible for the diverse muscle group response in muscular dystrophy are only partially understood.

In terms of the susceptibility of skeletal muscle fibers, it is known that both type I and II fibers are known to be affected in the animal models for deficiency of dystrophin and dystrophin-binding proteins such as $m d x$ mice, dy/dy mice, BIO 14.6 hamsters [36] and canine X-linked muscular dystrophy [39]. In human, type II fibers exhibit heightened sensitivity to primary dystrophin deficiency [41]. However, both type I and type II fibers are eventually affected in DMD patients.

In rasH2 mice, only type II skeletal muscle fibers were considered susceptible because myopathic changes were seen in type II fibers predominant skeletal muscles (biceps femoris, triceps brachii and gastrocnemial muscles), and were not seen in the soleus muscle, which consisted of type I fibers [8], even in the older rasH2 mice having apparent muscular lesions in affected muscles. The reason for this difference in susceptibility between type I and II muscle fibers is unknown. The diverse muscle group response and susceptibility in difference between muscle fiber types are thought to be important factors to explore the mechanisms of muscular degeneration, however, a clear explanation for this diversity has not yet been established. Porter et al. [28] recently addressed the diverse response in phenotypes of the $m d x$ diaphragm and hindlimb muscle using DNA array. This kind of research provides important information for the mechanism of muscular wasting and for the development of a medical cure for muscular dystrophy. The rasH2 mouse might be a useful model for exploring this diversity of phenotypes in muscular degeneration based on the muscle fiber type, since susceptibility to myopathy was different among muscles or muscle fiber types in the rasH2 mouse. Only type II fiber is also known to be affected in the chicken muscular dystrophy model [1, 23, 33]. But, a mouse model is thought to have an advantage in the view of ease of maintain and handle.

In electron microscopic observation, dilatation of the sarcoplasmic reticulum and indistinct Z-band suggesting excessive contraction were observed in the 10-13-week-old rasH2 mice. Considering the fact that other organelles were unaffected, these findings were thought to represent the early stage of degeneration. Dilatation of the sarcoplasmic reticulum was also confirmed in the $m d x$ mouse and DMD as the earliest change [7]. This has been associated with calcium overloading of the fibers, either experimentally or by mechanical damage [34]. We confirmed a focally indistinct Z-line, which was very similar to the Z-line loss frequently 
seen in the $m d x$ mouse and DMD [7]. This change is reportedly observed in light microscopic opaque fibers as a common finding in the $m d x$ mouse and DMD [36, 38], and is thought to be due to hypercontraction of muscle fibers [22]. Opaque fiber is common finding in $m d x$ mouse and DMD, however, it is not a specific change in muscular dystrophy, but is also seen in another muscular disorders such as polymyositis or in chemical induced myopathy [22]. We did not see obvious opaque fibers by light microscopic observations in this study; therefore, the extent of Z-line loss in rasH2 mice was thought to be relatively limited.

In summary, the skeletal myopathy occurring in rasH2 mice is consistent with muscular dystrophy characterized morphologically by progressive degeneration and regeneration of myofibers. The myopathy is confined to the type II fiber predominant muscles and is not associated with any pathognomonic lesions. These characteristics will provide us with a useful model for research in muscular dystrophy of diverse myofibers.

\section{REFERENCES}

1. Ashmore, C. R. and Doerr, L. 1971. Postnatal development of fiber types in normal and dystrophic skeletal muscle of the chick. Exp. Neurol. 30: 431-446.

2. Bittner, R. E., Anderson, L. V., Burkhardt, E., Bashir, R., Vafiadaki, E., Ivanova, S., Raffelsberger, T., Maerk, I., Hoger, H., Jung, M., Karbasiyan, M., Storch, M., Lassmann, H., Moss, J. A., Davison, K., Harrison, R., Bushby, K. M. and Reis, A. 1999. Dysferlin deletion in SJL mice (SJL-Dysf) defines a natural model for limb girdle muscular dystrophy 2B. Nat. Genet. 23: 141-142.

3. Bulfield, G., Siller, W. G., Wight, P. A. and Moore, K. J. 1984. $\mathrm{X}$ chromosome-linked muscular dystrophy $(m d x)$ in the mouse. Proc. Natl. Acad. Sci. U.S.A. 81: 1189-1192.

4. Carpenter, J. L., Hoffman, E. P., Romanul, F. C., Kunkel, L. M., Rosales, R. K., Ma, N. S., Dasbach, J. J., Rae, J. F., Moore, F. M., McAfee, M. B. and Pearce, L. K. 1989. Feline muscular dystrophy with dystrophin deficiency. Am. J. Pathol. 135: 909919.

5. Cohn, R. D. and Campbell, K. P. 2000. Molecular basis of muscular dystrophies. Muscle. Nerve. 23: 1456-1471.

6. Cooper, B. J., Winand, N. J., Stedman, H., Valentine, B. A., Hoffman, E. P., Kunkel, L. M., Scott, M. O., Fischbeck, K. H., Kornegay, J. N., Avery, R. J., Williams, J. R., Schmickel, R. D. and Sylvester, J.E. 1988. The homologue of the Duchenne locus is defective in X-linked muscular dystrophy of dogs. Nature (Lond.) 334: 154-156.

7. Cullen, M. J. and Jaros, E. 1988. Ultrastructure of the skeletal muscle in the $\mathrm{X}$ chromosome-linked dystrophic $(m d x)$ mouse. Comparison with Duchenne muscular dystrophy. Acta Neuropathol. (Berl.) 77: 69-81.

8. Donald McGavin, M. 1991.Procedures for morphologic studies of skeletal muscle, rat, mouse, and hamster. pp. 101-108. In: Cardiovascular and Musculoskeletal Systems (Jones, T. C., Mohr, U. and Hunt, R. D. eds.), Springer-Verlag, Berlin.

9. Dowling, P., Culligan, K. and Ohlendieck, K. 2002. Distal $m d x$ muscle groups exhibiting up-regulation of utrophin and rescue of dystrophin-associated glycoproteins exemplify a protected phenotype in muscular dystrophy. Naturwissenschaften 89: 75-78.
10. Dowling, P., Lohan, J. and Ohlendieck, K. 2003. Comparative analysis of Dp427-deficient $m d x$ tissues shows that the milder dystrophic phenotype of extraocular and toe muscle fibres is associated with a persistent expression of beta-dystroglycan. Eur. J. Cell. Biol. 82: 222-230.

11. Emery, A. E. 2002. The muscular dystrophies. Lancet 359: 687-695.

12. Engel, A. G. and Gomez, M. R. 1967. Nemaline ( $Z$ disk) myopathy: observations on the origin, structure, and solubility properties of the nemaline structures. J. Neuropathol. Exp. Neurol. 26: 601-619.

13. Gordon, E. S. and Hoffman, E. P. 2001. The ABC's of limbgirdle muscular dystrophy: alpha-sarcoglycanopathy, Bethlem myopathy, calpainopathy and more. Curr. Opin. Neurol. 14: 567-573.

14. Heffner, R. R. 1989. Muscle biopsy in neuromuscular disorders. pp. 119-139. In: Diagnostic Surgical Pathology (Sternberg, S. ed.), Raven Press Ltd., New York.

15. Hoffman, E. P. 2001. Dystrophinopathies. pp. 385-432. In: Disorders of Voluntary Muscle (Karpati, G., Hilton-Jones, D., Griggs, R. eds.), Cambridge Univ. Press, Cambridge, UK.

16. Hoffman, E. P. and Kunkel, L. M. 1989. Dystrophin abnormalities in Duchenne/Becker muscular dystrophy. Neuron 2: 1019-1029.

17. Homburger, F., Baker, J. R., Nixon, C. W. and Whitney, R. 1962. Primary, generalized polymyopathy and cardiac necrosis in an inbred line of Syrian hamsters. Med. Exp. 6: 339-345.

18. Meier, H. and Southard, J. L. 1970. Muscular dystrophy in the mouse caused by an allele at the dy-locus. Life. Sci. 9: 137 144.

19. Michelson, A. M., Russell, E. S. and Hoffman, P. J. 1955. Dystrophia muscularis: a hereditary primary myopathy in the house mouse. Proc. Natl. Acad. Sci. U. S. A. 41: 1079-1084.

20. Montgomery, C. A. 1978. Muscle diseases. pp. 821-887. In: Pathology of Laboratory Animals (Benirschke, K., Garner, F. and Jones, T. eds.), Springer-Verlag, New York.

21. Nigro, V., Okazaki, Y., Belsito, A., Piluso, G., Matsuda, Y., Politano, L., Nigro, G., Ventura, C., Abbondanza, C., Molinari, A. M., Acampora, D., Nishimura, M., Hayashizaki, Y. and Puca, G. A. 1997. Identification of the Syrian hamster cardiomyopathy gene. Hum. Mol. Genet. 6: 601-607.

22. Nonaka, I. 1994. Muscle pathologic diagnosis-mechanism in muscle fiber degeneration. Rinsho Shinkeigaku 34: 1279-1281 (in Japanese).

23. Nonaka, I. and Sugita, H. 1981. Intracytoplasmic vacuoles in alpha W fibers of dystrophic chicken muscle-probable early pathologic event initiates massive fiber necrosis. Acta Neuropathol. (Berl.) 55: 173-181.

24. Pagel, C. N. and Partridge, T. A. 1999. Covert persistence of $m d x$ mouse myopathy is revealed by acute and chronic effects of irradiation. J. Neurol. Sci. 164: 103-116.

25. Palmucci, L., Schiffer, D., Monga, G., Mollo, F. and de Marchi, M. 1978. Central core disease: histochemical and ultrastructural study of muscle biopsies of father and daughter. $J$. Neurol. 218: 55-62.

26. Porter, J. D. 1998. Commentary: extraocular muscle sparing in muscular dystrophy: a critical evaluation of potential protective mechanisms. Neuromuscul. Disord. 8: 198-203.

27. Porter, J. D., Rafael, J. A., Ragusa, R. J., Brueckner, J. K., Trickett, J. I. and Davies, K. E. 1998. The sparing of extraocular muscle in dystrophinopathy is lost in mice lacking utrophin and dystrophin. J. Cell. Sci. 111 (Pt 13): 1801-1811.

28. Porter, J. D., Merriam, A. P., Leahy, P., Gong, B., Feuerman, 
J., Cheng, G. and Khanna, S. 2004. Temporal gene expression profiling of dystrophin-deficient $(m d x)$ mouse diaphragm identifies conserved and muscle group-specific mechanisms in the pathogenesis of muscular dystrophy. Hum. Mol. Genet. 13: 257-269.

29. Robinson, D. 1998. The International Life Sciences Institute's role in the evaluation of alternative methodologies for the assessment of carcinogenic risk. Toxicol. Pathol. 26: 474-475.

30. Rosenberg, R. N., Prusiner, S. B., DiMauro, S., Barchi, R. L. and Kunkel, L. M. 1993. The Molecular and Genetic Basis of Neurological Disease, Butterworth-Heinemann, Boston.

31. Saitoh, A., Kimura, M., Takahashi, R., Yokoyama, M., Nomura, T., Izawa, M., Sekiya, T., Nishimura, S. and Katsuki, M. 1990. Most tumors in transgenic mice with human c-Ha-ras gene contained somatically activated transgenes. Oncogene 5: $1195-1200$.

32. Sakamoto, A., Ono, K., Abe, M., Jasmin, G., Eki, T., Murakami, Y., Masaki, T., Toyo-oka, T. and Hanaoka, F. 1997. Both hypertrophic and dilated cardiomyopathies are caused by mutation of the same gene, delta-sarcoglycan, in hamster: an animal model of disrupted dystrophin-associated glycoprotein complex. Proc. Natl. Acad. Sci. U.S.A. 94: 13873-13878.

33. Shafiq, S. A., Askanas, V. and Milhorat, A. T. 1971. Fiber types and preclinical changes in chicken muscular dystrophy. Arch. Neurol. 25: 560-571.

34. Somlyo, A. V., Gonzalez-Serratos, H. G., Shuman, H., McClellan, G. and Somlyo, A. P. 1981. Calcium release and ionic changes in the sarcoplasmic reticulum of tetanized muscle: an electron-probe study. J. Cell. Biol. 90: 577-594.

35. Suemizu, H., Muguruma, K., Maruyama, C., Tomisawa, M., Kimura, M., Hioki, K., Shimozawa, N., Ohnishi, Y., Tamaoki, N. and Nomura, T. 2002. Transgene stability and features of rasH2 mice as an animal model for short-term carcinogenicity testing. Mol. Carcinog. 34: 1-9.

36. Tanabe, Y., Woo, M. and Nonaka, I. 1991. X chromosomelinked muscular dystrophy $(m d x)$ of the skeletal muscle, mouse. pp. 149-155. In: Cardiovascular and Musculoskeletal Systems (Jones, T. C., Mohr, U. and Hunt, R. D. eds.), Springer-Verlag, Berlin.

37. Tsuchiya, T., Kobayashi, K., Sakairi, T., Goto, K., Okada, M., Sano, F., Sugimoto, J., Morohashi, T., Usui, T. and Mutai, M. 2002. Skeletal myopathy in transgenic mice carrying human prototype c-Ha-ras gene. Toxicol. Pathol. 30: 501-506.

38. Uchino, M., Araki, S. and Yoshida, O. 1985. The mechanism of muscle fiber breakdown in Duchenne muscular dystrophywith particular reference to the significance of opaque muscle fibers. Rinsho Shinkeigaku 25: 944-948.

39. Valentine, B. A., Winand, N. J., Pradhan, D., Moise, N. S., de Lahunta, A., Kornegay, J. N. and Cooper, B. J. 1992. Canine $\mathrm{X}$-linked muscular dystrophy as an animal model of Duchenne muscular dystrophy: a review. Am. J. Med. Genet. 42: 352356.

40. Watchko, J. F., O'Day, T. L. and Hoffman, E. P. 2002. Functional characteristics of dystrophic skeletal muscle: insights from animal models. J. Appl. Physiol. 93: 407-417.

41. Webster, C., Silberstein, L., Hays, A. P. and Blau, H. M. 1988. Fast muscle fibers are preferentially affected in Duchenne muscular dystrophy. Cell 52: 503-513.

42. Xu, H., Christmas, P., Wu, X. R., Wewer, U. M. and Engvall, E. 1994. Defective muscle basement membrane and lack of Mlaminin in the dystrophic dy/dy mouse. Proc. Natl. Acad. Sci. U.S.A. 91: 5572-5576.

43. Yamamoto, S., Urano, K., Koizumi, H., Wakana, S., Hioki, K., Mitsumori, K., Kurokawa, Y., Hayashi, Y. and Nomura, T. 1998. Validation of transgenic mice carrying the human prototype c-Ha-ras gene as a bioassay model for rapid carcinogenicity testing. Environ. Health Perspect. 106 (Suppl. 1): 57-69. 